\title{
Ischemia-Reperfusion Injury of Adipofascial Tissue: An Experimental Study Evaluating Early Histologic and Biochemical Alterations in Rats
}

\author{
Yusuf Kenan Coban, ${ }^{1}$ Ergul Belge Kurutas, ${ }^{2}$ and Harun Ciralik ${ }^{3}$ \\ ${ }^{1}$ Department of Plastic Surgery, Medical Faculty, Sutcuimam University, 46050 Kahramanmaras, Turkey \\ ${ }^{2}$ Department of Biochemistry, Medical Faculty, Sutcuimam University, 46050 Kahramanmaras, Turkey \\ ${ }^{3}$ Department of Pathology, Medical Faculty, Sutcuimam University, 46050 Kahramanmaras, Turkey
}

Received 17 May 2005; accepted 2 June 2005

\begin{abstract}
Fat necrosis remains a serious complication in reconstructive flaps. In clinical setting, it is well known that fat tissue is more susceptible to ischemic events. We aimed to evaluate early histological and biochemical changes of adipofascial tissue in an experimantal model. An epigastric flap model in rats was used to evaluate the effect of ischemia-reperfusion (I-R) injury on adipofascial tissue. Two groups of animals (one with ischemia alone and other ischemia-reperfusion group) were used to evaluate the degree of histological edema, congestion and extravascular bleeding, and early biochemical alterations within the adipofascial flaps. The biochemical parameters included glutathione (GSH) and malondialdehyde (MDA). In each group, contralateral groin subcutaneous adipose tissue served as control. These evaluations were compared to normal unmanipulated, contralateral abdominal subcutaneous adipose tissue. The ischemia-reperfused flap group showed histologically significantly much edema congestion and bleeding than the control groups $(P<.0001)$. The control group showed less edema in fat tissue than the ischemia-alone group $(P<.05)$. All of the flaps in the ischemia-only group showed significantly less bleeding and edema than I-R group $(P<.001)$. The ratio of MDA/GSH was 33 in control, 37 in ischemia alone, and 82 in ischemia-reperfusion groups, respectively. This study confirms that significant histologic and biochemical alteration occurs after ischemia and ischemia-reperfusion events in adipose tissue. Marked drop in adipose tissue antioxidant levels after I-R suggested that preemptive measures to this decrease should be undertaken in clinical settings.
\end{abstract}

\section{INTRODUCTION}

Fat necrosis remains a serious problem in reconstructive flaps and can range from a relatively minor spontaneously resolving complication to a major complication resulting in infection and liquefaction that requires surgical drainage. In extreme cases, fat necrosis may result in a partial flap loss requiring a second operation to excise the necrotic fat and recontour the remaining uninvolved tissue. There is a clinical perception that obese patients are at higher risk for postoperative complications following breast reconstruction using autologous tissue [1]. Ischemia appears to be the inciting event in the etiology of fat necrosis which can be a source for sepsis, especially when it is used as a graft material [2].

Reactive oxygen species (ROS) production occurs as a consequence of the endogenous reactions and plays an important role in normal cellular function. Increased formation of ROS and/or decreased antioxidant defence can

Correspondence and reprint requests to Y. K. Coban, Department of Plastic Surgery, Medical Faculty, Sutcuimam University, 46050 Kahramanmaras, Turkey; kenancoban@ksu.edu.tr be defined as oxidative stress, which is widely recognized as an important feature of many diseases. Lipid peroxidation is one of the most important expression of oxidative stress induced by ROS. Lipid peroxidation is a normal phenomenon that occurs continuously at low levels in all living cells [3]. These peroxidation reactions are in part toxic to cells and cell membranes; however, they are normally controlled by countervailing biologic mechanisms.

Ischemia-reperfusion is well known entity and has been shown to occur in different tissue types and organs [4]. Any ischemia-reperfusion study of adipofascial tissue may be a value of clinical significance and may represent a model for future studies. In this experimental study, we aimed to clarify the histopathologic and biochemical changes after I-R of fat tissue in a rat epigastric island flap model. According to our extensive literature search, this was not documented before.

\section{MATERIALS AND METHODS}

\section{Animals}

Non-inbred wistar albino adult (male) rats, weighing between $200 \mathrm{~g}$ and $250 \mathrm{~g}$ were obtained from the Medical Sciences Experimental Research Center of the University 
TABLE 1. Scales for edema and congestion in flap adipose tissue.

\begin{tabular}{cccc}
\hline Grade & Edema & Congestion & Bleeding \\
\hline 0 & No edema & Normal adipose tissue & No bleeding \\
1 & Minimal edema & Minimal congestion & Minimal \\
2 & Edema $<25 \%$ of section & Fat congestion $<25 \%$ of section & Moderate \\
3 & Edema $>25 \%$ to $<50 \%$ of section & Fat congestion $>25 \%$ to $<50 \%$ of section & Excessive \\
4 & Edema $>50 \%$ to $<75 \%$ of section & Fat congestion $>50 \%$ to $<75 \%$ of section & - \\
5 & Edema $>75 \%$ of section & Fat congestion $>75 \%$ of section & - \\
\hline
\end{tabular}

of Sutcuimam. The study was approved by KSU Ethical Committe of Medical Faculty. They were fed with a standard laboratory diet and tap water. Illumination was 12 hour light/dark cycle and room temperature was 22$24^{\circ} \mathrm{C}$.

A total of 20 adult male wistar rats were used in the study with institutional animal care and use committee approval. The rats were randomly divided into two groups.

(1) Group 1 contained 10 rats (ischemia-alone group). In this group, the specimens were taken from subcutaneous adipose tissue of the epigastric flaps after the completion of 1.5 hours of ischemia (without reperfusion).

(2) Group 2 (10 rats). The flaps in this group were subjected to 1.5 hours of ischemia and 1 hour of reperfusion. The subcutaneous adipofascial specimens were taken at time of end of the reperfusion in the second group (I-R group). In each group, contralateral groin subcutaneous fat tissue served as control. All specimens were subjected to histopathological and biochemical analysis.

\section{Flap model}

All operations on the rats were performed under intraperitoneal sodium pentabarbital anesthesia, $35 \mathrm{mg} / \mathrm{kg}$ body weight, using aseptic surgical techniques. Parenteral anesthesia maintanence was obtained by pentabarbital at a dose of $30 \mathrm{mg} / \mathrm{kg}$ intraperitoneally [5]. Once the animals were anesthetized, the abdomens were shaved and the skin prepared with povidone-iodine and 70\% isopropyl alcohol. Then a right epigastric flap based on epigastric artery and vein in a diameter of $2 \times 2 \mathrm{~cm}$ was elevated. Periareolar adipose tissue was included into the flap. This flap model has been extensively studied and validated for adipocutaneous, fasciocutaneous, and cutaneous tissues $[6,7,8,9]$. Acland V3 clamps for pedicle clamping were used to induce complete flap ischemia. For reperfusion at the end of the ischemia the clamps were removed from the pedicle and the vascular flow observed with microscobic examination. No vasospasm or complication occurred.

\section{Preparation of homogenate}

The subcutaneous tissues obtained from flaps and contralateral groins were quickly removed, weighed, blotted on filter paper, and homogenized with three volumes of ice-cold $1.15 \%$ KCI. The levels of GSH and MDA were measured in the supernatant obtained from centrifugation at $14000 \mathrm{rpm}$.

\section{Biochemical analysis}

GSH level was measured in the tissue samples according to Beutler et al [10]. The reaction mixture contains filtrate, phosphate buffer, and DTNB (5, 5' -dithiobis 2nitrobenzoic acid) in a final volume of $10 \mathrm{~mL}$. A blank is prepared by using precipitating reagent and distilled water instead of filtrate. The absorbances are read in a spectrophotometer immediately at $412 \mathrm{~nm}$ wavelength before and after addition of DTNB. The values were determined from the standard curve. GSH level was expressed as mi$\mathrm{cromol} / \mathrm{mg}$ protein.

Malondialdehyde level in the tissue samples was measured with the thiobarbituric acid (TBA) test [11]. The reaction mixture contained $0.1 \mathrm{~mL}$ sample, $0.2 \mathrm{~mL}$ of $8.1 \%$ sodium dodecyl sulphate (SDS), $1.5 \mathrm{~mL}$ of $20 \%$ acetic acid, and $1.5 \mathrm{~mL}$ of $0.8 \%$ aqueous solution of TBA. The mixture $\mathrm{pH}$ was adjusted to 3.5 and volume was finally made up to $4.0 \mathrm{~mL}$ with distilled water and $5.0 \mathrm{~mL}$ of the mixture of $n$-butanol and pyridine $(15: 1, \mathrm{v} / \mathrm{v})$ was added. The mixture was shaken vigorously. After centrifugation at $4000 \mathrm{rpm}$ for $10 \mathrm{~min}$, the absorbance of the organic layer was measured at $532 \mathrm{~nm}$.

The protein concentration of the tissue samples was measured with Spectronic-UV 120 spectrophotometer by the method of Lowry et al [12].

\section{Histopathological evaluation}

At the postoperative hour 1 , the animals were sacrificed and the fat harvested from the flaps, fixed, sectioned, and stained with hematoxylin and eosin ( $\mathrm{H} \& \mathrm{E})$. The histologic sections were evaluated by a blinded pathologist to determine the degree of fat congestion, edema, and bleeding. A standard measuring grid was used in all assessments. The representative biopsies were graded on a five-point scale. The bleeding scale ranked the specimens from 0 (no bleeding) to 3 (excessive bleeding changes in greater than $75 \%$ of the specimen). Similarly, fat tissue was ranked 0 to 5 with 0 being normal healthy fat, and 5 being severe edema and congestion over $75 \%$ of the specimen (Table 1). Of the various sections evaluated for each flap, a mode number was determined for the edema scale and the fat congestion scale for each rat, and a histologic scorring was determined. 
TABle 2. Adipose tissue MDA/GSH ratios in groups are shown as mean \pm standard deviation.

\begin{tabular}{cc}
\hline Groups & $\begin{array}{l}\text { MDA (nmol/mg protein)/GSH } \\
\text { (micromol/mg protein) Ratio }\end{array}$ \\
\hline Ischemia only & $36.9 \pm 2.1$ \\
Control of ischemia & $32.65 \pm 2$ \\
Ischemia-reperfusion & $73.5 \pm 5.8$ \\
Control of I-R & $33.1 \pm 1.8$ \\
\hline
\end{tabular}

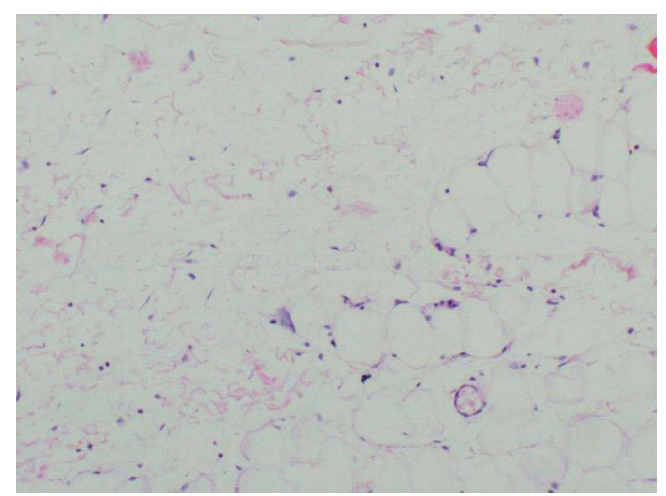

FIgURE 1. Marked edema in the adipose tissue after ischemia is seen $(\mathrm{H} \& \mathrm{E}, \times 50)$.

\section{Statistical analysis}

All the data were expressed as mean \pm standard deviation. The comparisons between the groups and their controls were made by using paired $t$ test. The unpaired $t$ test for independent groups was used to compare the data of ischemia-reperfusion and ischemia-alone groups. Comparison of the means of the edema, congestion, and bleeding scale ranks of each of I-R groups to the ischemiaalone group was performed using Wilcoxon test. Similarly, the comparison of the histologic rank scores between the groups and their controls was made by using MannWhitney $U$ test. A $P$ value less than 0.05 was considered as significant.

\section{RESULTS}

Table 2 shows the means \pm standarddeviation of tissue MDA and GSH levels. GSH levels in ischemia-reperfusion groups were significantly lower than control $(P<.001)$. MDA levels in ischemia-reperfusion group were significantly higher than control $(P<.001)$. The MDA levels in ischemia-alone group were also lower than control, but the level of significance at .029 of $P$ value. Although GSH levels in ischemia-alone group are lower than control, this difference did not gain statistically significance $(P>.05)$. The ratio of MDA/GSH was 33 in control, 37 in ischemia-alone, and 82 in ischemia-reperfusion groups, respectively.

Histologic sections showed that all of ischemia-alone flaps had grade 3-4 edema without congestion (Figure 1).

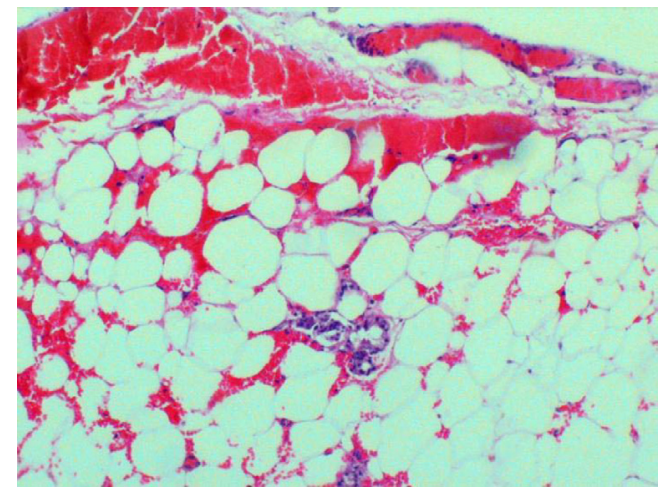

FIGURE 2. Congestion in the vessels with marked edema and hemorrhage in the adipose tissue are seen after ischemiareperfusion $(\mathrm{H} \& \mathrm{E}, \times 50)$.

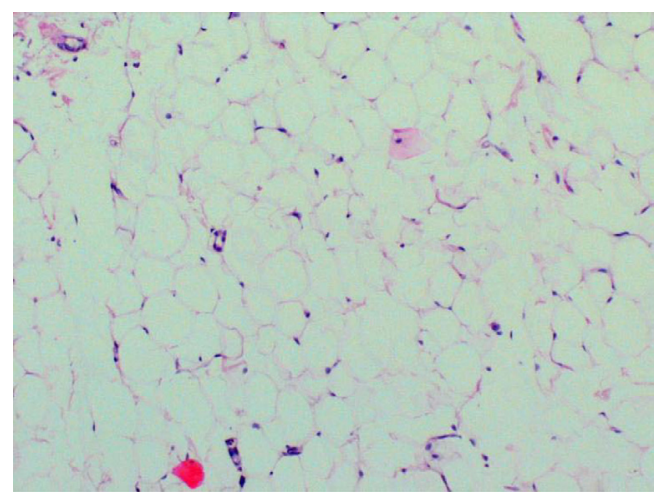

Figure 3. Normal adipose tissue $(\mathrm{H} \& \mathrm{E}, \times 50)$.

There was no bleeding (grade 0 ) in the flaps of this group. In contrast to ischemia flaps, all the flaps in I-R group had excessive bleeding (grade 3 ) in addition to grade 3-4 congestion and edema (Figure 2). Normally, control fat tissue samples had no edema, congestion, or bleeding (Figure $3)$. The histologic findings of two groups showed a significant difference $(P<.001)$. All numeric histologic gradings for each rat in groups were presented in Table 3. Histologically, the findings in groups coincided with the biochemical alterations in groups. In other words, the most biochemical substantial changes were seen in flaps with the worst histologic scores.

\section{DISCUSSION}

Glutathione (GSH, $\gamma$-glutamyl cysteinylglycine), the most important low molecular weight nonenzymatic antioxidant, is cellular antioxidant, which protects cells from oxidative stress. GSH as substrate for glutathione peroxidase plays an essential protective role against reactive oxygen species that are generated during the metabolism of many xenobiotics and some degree of oxidative stress under physiologic conditions. It is an ubiquitous cellular constituent that is the most abundant thiol reducing agent 
TABLE 3. Histologic grading results are seen for each rat within groups; $\mathrm{H}=$ hemorrhagia, $\mathrm{E}=\mathrm{edema}, \mathrm{C}=$ congestion; $\mathrm{Isc}=$ ischemiaonly group, I-R = ischemia-reperfusion.

\begin{tabular}{|c|c|c|c|c|c|c|c|c|c|}
\hline \multicolumn{10}{|c|}{ Histologic grading scores } \\
\hline \multirow[b]{2}{*}{ Rat no. } & \multicolumn{3}{|c|}{$\mathrm{I}-\mathrm{R}$} & \multicolumn{3}{|c|}{ Ischemia alone } & \multicolumn{3}{|c|}{ Control } \\
\hline & $\mathrm{H}$ & $\mathrm{E}$ & $\mathrm{C}$ & $\mathrm{H}$ & $\mathrm{E}$ & $\mathrm{C}$ & $\mathrm{H}$ & E & $\mathrm{C}$ \\
\hline 1 & 3 & 4 & 3 & 0 & 3 & 0 & 0 & 0 & 0 \\
\hline 2 & 3 & 5 & 5 & 0 & 2 & 0 & 0 & 0 & 0 \\
\hline 3 & 3 & 4 & 5 & 0 & 3 & 0 & 0 & 0 & 0 \\
\hline 4 & 3 & 4 & 4 & 0 & 3 & 0 & 0 & 0 & 0 \\
\hline 5 & 3 & 5 & 4 & 0 & 2 & 0 & 0 & 0 & 0 \\
\hline 6 & 3 & 4 & 4 & 0 & 2 & 0 & 0 & 0 & 0 \\
\hline 7 & 3 & 3 & 4 & 0 & 3 & 0 & 0 & 0 & 0 \\
\hline 8 & 3 & 4 & 4 & 0 & 3 & 0 & 0 & 0 & 0 \\
\hline 9 & 3 & 5 & 4 & 0 & 2 & 0 & 0 & 0 & 0 \\
\hline 10 & 3 & 4 & 4 & 0 & 2 & 0 & 0 & 0 & 0 \\
\hline
\end{tabular}

in mammalian tissues [13]. Decreased cellular GSH content is a common finding in experimental and human diabetes, in which increased oxidative stress appears to occur [14]. It has been reported that decreased GSH concentrations in aging tissues might be due to increased utilization as a result of enhanced oxidation in the old mouse [15]. Thus glutathione depletion may be a useful tool studying peroxidative systems. I-R creates such an increased peroxidation environment in living tissues. Leichtweis and Ji showed that GSH depletion by inhibition of its synthesis and transport can exacerbate cardiac dysfunction inflicted by in vivo ischemia-reperfusion [16]. They concluded that the aetiology might involve impaired myocardial antioxidant defenses and whole-body GSH homeostasis. In this study, we found that MDA level in adipose tissue was increased twofold higher after ischemia-perfusion. Adipose tissue MDA levels increased before reperfusion (ischemiaonly group), but this increase was much more profound in reperfusion group $(P<.05$ versus $P<.001)$. MDA levels may not be a measure for oxidative stress by itself, but related to the scavenger function of GSH as the ratio indicates. Increased lipid peroxidation and decreased glutathione levels were detected in both groups compared to their controls $(P<.05)$. The ratio of lipid peroxidation/total antioxidant activity (MDA/GSH) was increased in ischemia-reperfusion which indicates that oxidative stress appears to occur. This may be due to increased cell turnover or decreased antioxidant free radical scavenging mechanisms [13]. This study is first to show that the ratio of MDA/GSH gradually increases from the first minutes of reperfusion to the end of reperfusion. Free radicals are known to increase membrane permeability and inactivate the receptors in membrane and enzymes by lipid peroxidation as being an important membrane component that causes membrane disflow. They occur both in cytoplasm by cytochrome P450 2E1 system and in mitochondria [3]. The highly reactive free radicals generated during the course of the reaction are detoxified by GSH and/or by the electron acceptor NADPH produced by the glucose-6-phosphate dehydrogenase enzyme [13].
Malondialdehyde (MDA) is an indicator of lipid peroxidation which increases in various disease. Increased lipid peroxidation levels and decreased antioxidant protection generate epoxides that may spontaneously react with nucleophilic centers in the cell and thereby covalently bind to DNA, RNA, and protein [3]. Oxidative stress arises as a result of an imbalance between free radical production and antioxidant defence.

A degree of fat necrosis is the usual sequel when adipose tissue traumatized or manipulated by a surgical procedure. Fat necrosis may also change the volume and the contour of the involved tissue leading to an obvious aesthetic deformity. Patients who are morbidly obese are reported as having very high risk of failure and complications, and should avoid any type of TRAM flap breast reconstruction [14]. These clinical findings needs further support by animal studies. Current literature leads one to think that fat tissue is more succeptible to trauma and ischemic events $[15,16,17,18,19]$. Ultrastructural alterations are correlated with changes in susceptibility to lipid peroxidation in fat tissue. The results of these parallel studies indicate that both free-radical-dependent and -independent mechanisms operate in ischemia and reperfusion injury in flap tissue and that fat has a greater predisposition to free radical damage than skin. Free TRAM flaps were found to have a less fat necrosis when compared with pedicled TRAM flaps. This difference was attributable to having a better blood flow of the free TRAM flaps [20]. Rare partial and absent complete flap necrosis in the Erdmann's series was attributable to the delay in unipedicled flaps [21]. The epigastric adipocutaneous flap model was used for the second part of the experiment. The data showed that late remote ischemic preconditioning attenuated I-R injury in muscle flaps, whereas it was ineffective in adipocutaneous flaps [22]. Survival of aspirated fat cell grafts has been found as depending mainly on the anatomic site, the mobility, and the vascularity of the recipient tissue or underlying causes, and less on harvesting methods [23]. This study showed the importance of vascular supply in fat viability. 
Several key issues in the understanding of reperfusion injury are now clarified. First, ischemic changes are the necessary prerequisites, but are not in themselves sufficient. The experimental approach thus opens ample opportunities for the study of new therapeutic strategies, or for the reevaluation of the mode of action of already established therapies. For the adipose tissue, these changes were firstly demonstrated in this experimental model. Further studies are necessary to put forward preemptive measures of I-R injury of fat tissue. These measures may be useful in clinical setting.

As a conclusion, I-R of adipofascial tissue may cause oxidative stress, increase lipid peroxidation level leading to insufficiency in glutathione levels. Also, we believe that patients with ischemia-reperfusion may be benefited from antioxidant treatments. Transfer of adequate amounts of adipose tissue is often desirable in plastic surgery such as for breast reconstruction. Some degree of oxidative stress occurs in most, if not all, fat necrosis, and the major question to be answered is whether it makes a significant contribution to the fat necrosis.

\section{REFERENCES}

[1] Kroll SS, Netscher DT. Complications of TRAM flap breast reconstruction in obese patients. Plast Reconstr Surg. 1989;84(6):886-892.

[2] Valdatta L, Thione A, Buoro M, Tuinder S. A case of life-threatening sepsis after breast augmentation by fat injection. Aesthetic Plast Surg. 2001;25(5):347349.

[3] Halliwell B. Reactive oxygen species in living systems: source, biochemistry, and role in human disease. Am J Med. 1991;91(3C):14S-22S.

[4] Zhang F, Hu EC, Gerzenshtein J, Lei MP, Lineaweaver WC. The expression of proinflammatory cytokines in the rat muscle flap with ischemiareperfusion injury. Ann Plast Surg. 2005;54(3):313317.

[5] Wixson SK, White WJ, Hughes HC Jr, Lang CM, Marshall WK. A comparison of pentobarbital, fentanyl-droperidol, ketamine-xylazine and ketamine-diazepam anesthesia in adult male rats. Lab Anim Sci. 1987;37(6):726-730.

[6] Belmont MJ, Marabelle N, Mang TS, Wax MK. Effect of photodynamic therapy on the critical primary ischemic time of fasciocutaneous flaps. Laryngoscope. 1999;109(6):886-890.

[7] Qi Y, Gazelius B, Linderoth B, Löfgren O, Gribbe O, Lundeberg T. Arterial blood flow and microcirculatory changes in the rat groin flap after ischemia provocation by electrical stimulation of the artery. Microvasc Res. 2001;62(3):243-251.

[8] Lubiatowski P, Goldman CK, Gurunluoglu R, Carnevale K, Semionov M. Enhancement of epigastric skin flap by adenovirus-mediated VEGF gene therapy. Plast Reconstr Surg. 2001;109(6):1986-1993.
[9] Yuksel E, Weinfeld AB, Cleek R, et al. Augmentation of adipofascial flaps using the long-term local delivery of insulin and insulin-like growth factor-1. Plast Reconstr Surg. 2000;106(2):373-382.

[10] Beutler E, Villacorte D, Kuhl W, Guinto E, Srivastava S. Nonenzymatic conversion of human hexosaminidase A. J Lab Clin Med. 1975;86(2):195203.

[11] Ohkawa H, Ohishi N, Yagi K. Assay for lipid peroxides in animal tissues by thiobarbituric acid reaction. Analytical Biochemistry. 1979;95:351-358.

[12] Lowry OH, Rosebrough NJ, Farr AL, Randall RJ. Protein measurement with the Folin phenol reagent. J Biol Chem. 1951;193(1):265-275.

[13] Anderson ME. Glutathione: an overview of biosynthesis and modulation. Chem Biol Interact. 1998;111-112:1-14.

[14] Khamaisi M, Kavel O, Rosenstock M, et al. Effect of inhibition of glutathione synthesis on insulin action: in vivo and in vitro studies using buthionine sulfoximine. Biochem J. 2000;349(pt 2):579-586.

[15] Hazelton GA, Lang CA. Glutathione contents of tissues in the aging mouse. Biochem J. 1980;188(1):2530.

[16] Leichtweis S, Ji LL. Glutathione deficiency intensifies ischaemia-reperfusion induced cardiac dysfunction and oxidative stress. Acta Physiol Scand. 2001;172(1):1-10.

[17] Ilhan N, Ilhan N, Simsek M. The changes of trace elements, malondialdehyde levels and superoxide dismutase activities in pregnancy with or without preeclampsia. Clin Biochem. 2002;35(5):393-397.

[18] Chang DW, Wang B, Robb GL, et al. Effect of obesity on flap and donor-site complications in free transverse rectus abdominis myocutaneous flap breast reconstruction. Plast Reconstr Surg. 2000;105(5):16401648.

[19] Aqel NM, Howard A, Collier DS. Fat necrosis of the breast: a cytological and clinical study. Breast. 2001;10(4):342-345.

[20] Schoeller T, Gurunluoglu R, Schubert H, Hussl $\mathrm{H}$, Wechselberger G. Treatment of breast asymmetry with free adiposal flap from the lower abdomen: unsuccessful attempt. Plast Reconstr Surg. 2003;112(2):698-700.

[21] Tillmann C, Holst R, Swedman C. Traumatic fat necrosis of the breast: a case report. Acta Derm Venerol. 2003;83(3):227-228.

[22] Kroll SS. Fat necrosis in free transverse rectus abdominis myocutaneous and deep inferior epigastric perforator flaps. Plast Reconstr Surg. 2000;106(3):576-583.

[23] Nishikawa H, Gower JD, Fryer PR, Charlett A, Manek S, Green CJ. Ultrastructural changes and lipid peroxidation in rat adipomusculocutaneous flap isotransplants after normothermic storage and reperfusion. Transplantation. 1992;54(5):795-801. 


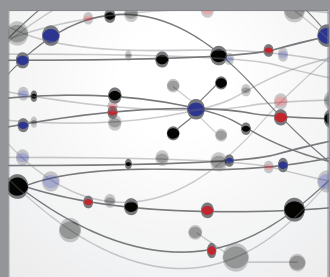

The Scientific World Journal
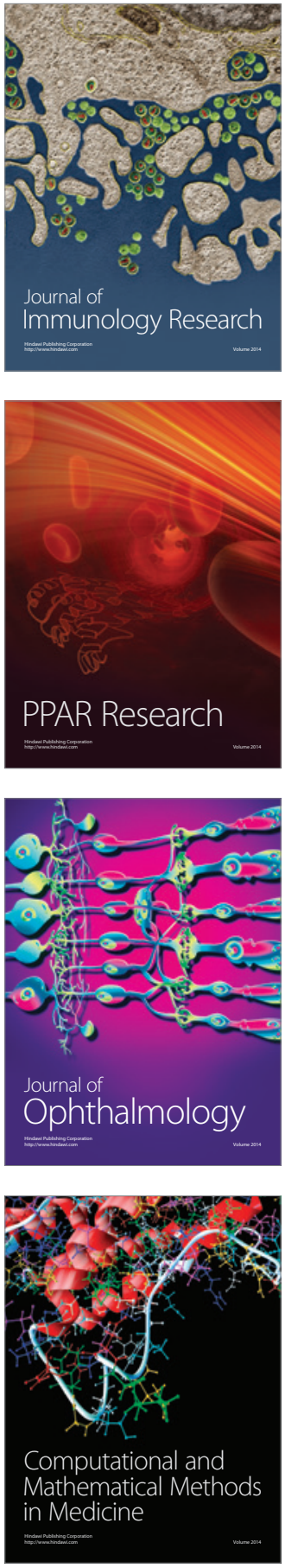

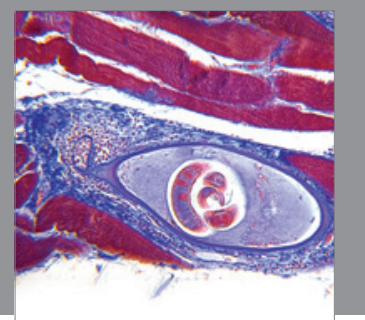

Gastroenterology

Research and Practice
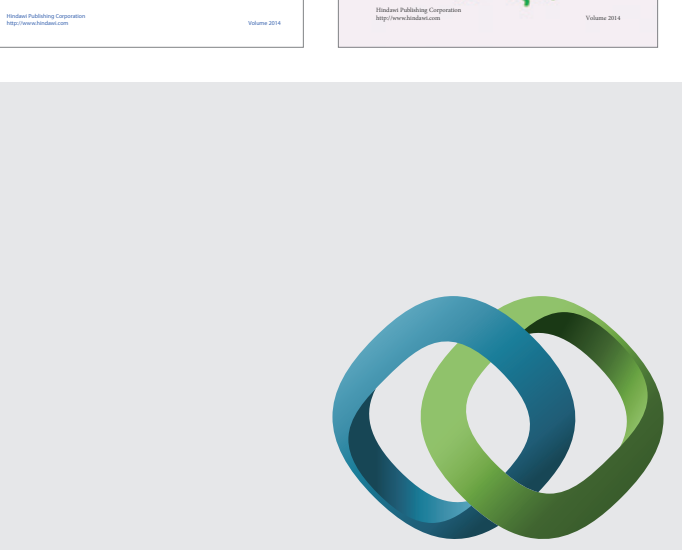

\section{Hindawi}

Submit your manuscripts at

http://www.hindawi.com
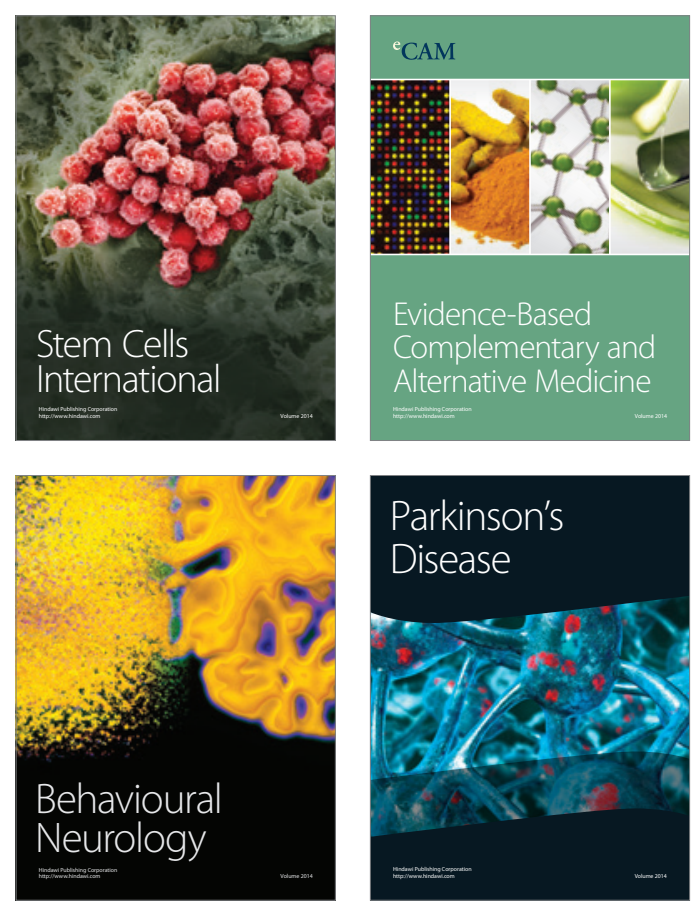

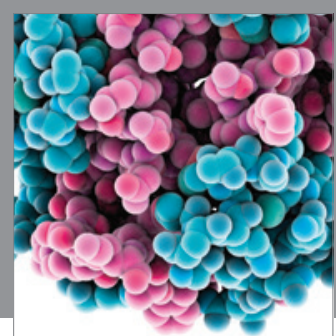

Journal of
Diabetes Research

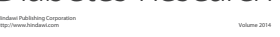

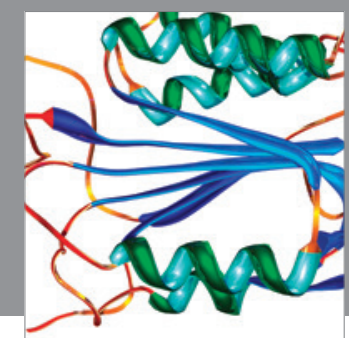

Disease Markers
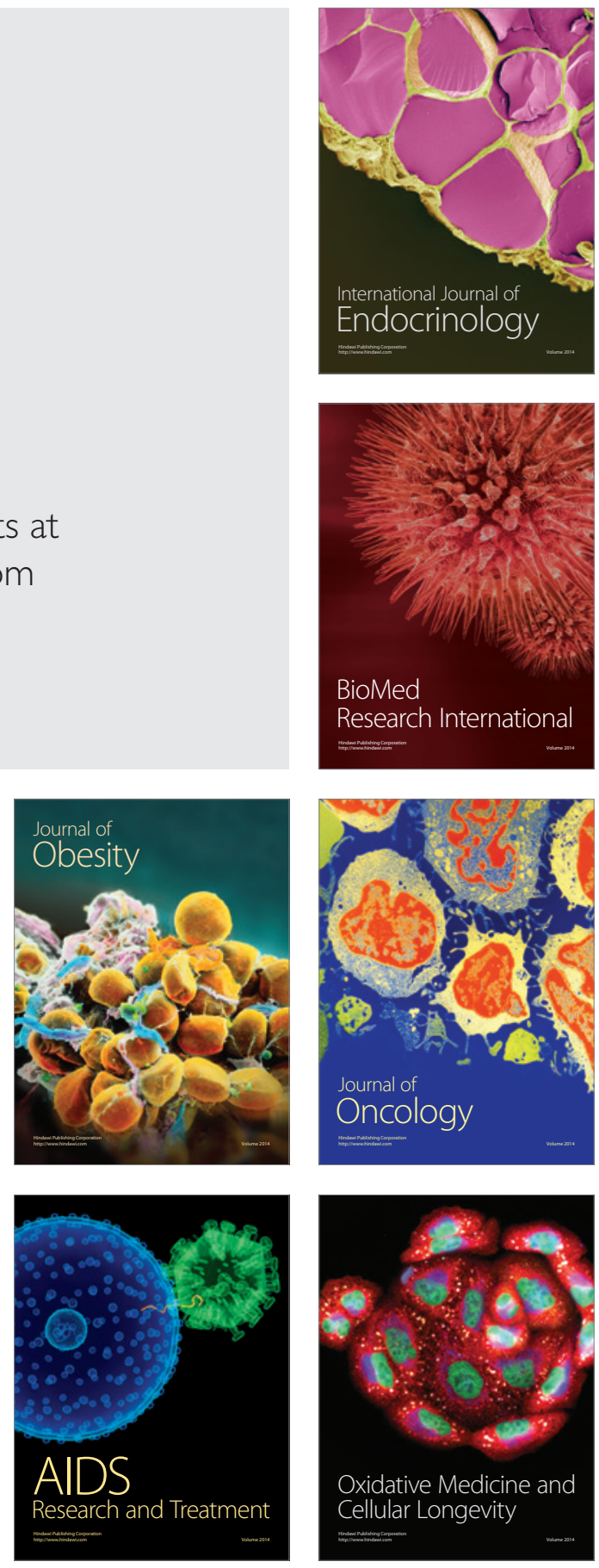